\title{
0 efeito do fim do Acordo sobre Têxteis e Vestuários para a indústria brasileira: uma análise a partir da fronteira de produção estocástica*
}

\author{
Diogo de Prince Mendonça \\ Fundação Getúlio Vargas (FGV/SP), São Paulo (SP), Brasil \\ Ariene da Silva Salgueiro \\ Universidade Federal do Paraná (UFPR), Curitiba (PR), Brasil \\ Rogério Gomes \\ Universidade Estadual Paulista "Júlio de Mesquita Filho" (Unesp), Araraquara (SP), Brasil
}

Recebido: 02/08/2011 Versão revisada (entregue): 15/02/2012 Aprovado: 27/04/2012

\begin{abstract}
Resumo
Este artigo investiga a produtividade e a função de produção de 13 grandes empresas têxteis e de vestuário brasileiras antes e depois do fim do Acordo sobre Têxteis e Vestuário (AVT), que extinguiu as cotas de importação em 2005. Com esse propósito, estima-se a fronteira de produção estocástica entre 1997 e 2008 em painel e, simultaneamente, uma equação explicativa para a (in)eficiência das firmas, como proposto por Battese e Coelli (1995). Os resultados indicaram que as empresas mais eficientes são as mais antigas. A produtividade total dos fatores das firmas apresentou tendência de queda, inclusive após o fim das cotas, aumentando a produtividade apenas a partir de 2007. De forma geral, no período as empresas de Santa Catarina foram mais eficientes do que as de outros Estados.
\end{abstract}

Nós somos gratos aos comentários dos pareceristas anônimos. Ainda agradecemos a Priscila Trigo e Herick Moralles que auxiliaram no início desse trabalho. 
Diogo de Prince Mendonça, Ariene da Silva Salgueiro, Rogério Gomes

Palavras-Chave | Produtividade; Fronteira de Produção Estocástica; Indústria Têxtil.

Código JEL | L20; F55; L67.

The effect of the end of the Agreement on Textiles and Clothing for the Brazilian industry: an analysis from the stochastic production frontier

\begin{abstract}
This article investigates the productivity and production function of thirteen large Brazilian textile and clothing companies before and after the end of the Agreement on Textiles and Clothing (AVT) that abolished import quotas in 2005. For this purpose, we estimate the stochastic production frontier in panel data between 1997 and 2008 and simultaneously an explanatory equation for the (in)efficiency of firms, as proposed by Battese and Coelli (1995). The results indicated that more efficient firms are the oldest. The total factor productivity of firms tended to fall, even after the end of quotas, increasing productivity only from 2007. Overall, firms from Santa Catarina were more efficient than those of other states.
\end{abstract}

KeYWORDs: Productivity; Stochastic Production Frontier; Textile Industry.

JEL-CODES | L20; F55; L67.

\title{
1. Introdução
}

É comum que as etapas iniciais do processo de industrialização de muitos países envolvam atividades relacionadas às indústrias têxteis e de vestuário. A razão econômica para isso reside no fato de que o baixo custo da mão de obra empregada, associado aos volumes relativamente pequenos de investimentos requeridos por algumas das tecnologias de produção, pode ser usado como um importante fator de competitividade. Ademais, ambas são indústrias intensivas em trabalho de pouca qualificação (LOPES, 1994; GEREFFI, 2006). Nesse sentido, tais indústrias são muitas vezes essenciais nas primeiras fases do desenvolvimento econômico de países com recursos escassos, especialmente em termos de formação técnico-profissional.

Desde 1950, em razão destas características, os países desenvolvidos procuraram proteger seus mercados e controlar, por meio de diferentes acordos, o comércio 
internacional de bens das indústrias têxteis e de vestuário. A partir de 1974, entrou em vigor o Acordo Multifibras - amplo em termos de nações participantes - para regular o comércio internacional estabelecendo cotas de importação.

Em 1994, além de algumas modificações na regulação anterior, foi firmado o Acordo sobre Têxteis e Vestuários (AVT), que estabelecia as diretrizes para um plano de liberalização gradual do comércio internacional desses produtos. Como o objetivo principal do AVT consistia na eliminação das cotas de importação até o final de 2004 (SEYOUM, 2007), surgiram críticos que vislumbravam nessas medidas de redução do protecionismo uma fonte de crise doméstica para as duas indústrias, em virtude da possibilidade de fechamento de empresas e redução nos postos de trabalho.

Como o fim das cotas de importação, alguns países asiáticos, em particular a China, surgem como o centro mais provável de abastecimento mundial, em razão das significativas vantagens em termos do volume disponível de mão de obra e dos custos relativos do trabalho, entre outras. Nessas circunstâncias, era esperado um deslocamento geográfico de parte da produção mundial que, consequentemente, elevaria as importações de muitos outros países. Procurando reduzir o impacto dessas mudanças, diversos países - inclusive o Brasil - estabeleceram um memorando de entendimentos com a China para resguardar a possibilidade de acionar salvaguardas até 2008 (NORDAS, 2004).

Assim, diante da eliminação das cotas de importação e do aumento da concorrência internacional, o comportamento das empresas dessas indústrias no Brasil surge como um tema relevante de pesquisa. O objetivo principal deste estudo é examinar a produtividade e a eficiência técnica de algumas grandes empresas brasileiras fabricantes de produtos têxteis e de vestuário, no sentido de averiguar as reações ao fim do acordo AVT, quando confrontadas com o período anterior à extinção das barreiras. Adicionalmente, como parte significativa das firmas selecionadas para análise concentra-se no Estado de Santa Catarina, um polo regional de produção do setor têxtil e de vestuário, este estudo também avalia a similaridade entre o comportamento das companhias catarinenses e o daquelas instaladas nos demais Estados. O método utilizado no trabalho é o da fronteira de produção estocástica para 13 grandes empresas têxteis brasileiras no período entre 1997 e 2008, formando um painel de dados.

Além desta introdução, o artigo está dividido em outras cinco partes. A segunda seção trata das especificidades do Acordo sobre Têxteis e Vestuários e algumas das consequências esperadas com a sua extinção. A terceira faz uma breve resenha das ca- 
Diogo de Prince Mendonça, Ariene da Silva Salgueiro, Rogério Gomes

racterísticas das indústrias brasileiras de produtos têxteis e do vestuário desde 1990. Na quarta seção, apresenta-se a metodologia de fronteira de produção estocástica utilizada no trabalho. A quinta traz os resultados relativos à função de produção estimada e a eficiência das empresas da amostra e, na sexta seção, são feitos alguns comentários finais.

\section{Os acordos sobre têxteis e vestuários}

Há décadas o comércio internacional de produtos têxteis e de vestuário tem sido regulado por acordos. Por se tratar de uma indústria tradicional e intensiva em mão de obra pouco qualificada, a liberalização do comércio destes produtos pode acarretar problemas sociais, isto é, desemprego nessas indústrias se o custo do fator trabalho for comparativamente mais elevado. Por isso, as negociações acerca de acordos comerciais estão, em geral, sujeitas ao poder de barganha e aos interesses específicos das partes interessadas (LOPES, 1994). Assim, a perspectiva de liberalização do comércio internacional das indústrias têxteis e de vestuário incentivou os países em desenvolvimento, na Rodada do Uruguai, a negociarem a participação do capital estrangeiro no setor de serviços e as regulamentaçôes sobre os direitos de propriedade intelectual (NORDAS, 2004), em troca da suspensão das cotas.

As medidas protecionistas nas indústrias de bens têxteis e de vestuário são anteriores a 1974. Entretanto, a partir desse ano entrou em vigor o Acordo Multifibras e o número de países participantes foi sendo gradualmente ampliado. $\mathrm{O}$ acordo tinha como base as negociações bilaterais e aceitava que os países desenvolvidos adotassem regulamentaçōes temporárias para defender a indústria nacional, ou seja, permitia que os países importadores aplicassem salvaguardas sobre o comércio de produtos têxteis e de vestuário. Como as cláusulas de proteção consentiam que fossem estabelecidas restrições às exportações de cada país (cotas de importação) e, adicionalmente, a adoção de tarifas à importação, o acordo acabava por destinar parcelas específicas dos mercados dos países importadores a determinados países exportadores, criando assim reservas de mercado e desvios de comércio.

Em 1994, o Acordo Multifibras foi adaptado às regras do GATT (Acordo Geral de Comércio e Tarifas), dando origem a uma nova regulamentação denominada Acordo sobre Têxteis e Vestuários (AVT). ${ }^{1} \mathrm{O}$ pacto previa a redução gradual do protecionismo e a eliminação das restrições quantitativas impostas aos bens têxteis e de vestuários. Tendo como referências os volumes de produtos importados em 1990, os países signatários do AVT estavam obrigados a reduzir as cotas estabeleci-

1 Posteriormente, os produtos têxteis e de vestuário passaram a ser submetidos às regras da OMC (Organização Mundial do Comércio), quando a instituição foi criada em substituição ao GATT. 
das em proporçôes não inferiores a 16\%, 18\% e 17\% (totalizando 51\%) nos anos de 1995, 1998 e 2002, respectivamente. O segundo conjunto de produtos, que representavam os demais 49\% das importaçōes de 1990, deveria ser liberado das restrições das cotas a partir de janeiro de 2005.

Ao mesmo tempo, para evitar um retrocesso com medidas protecionistas após o início do AVT, impedia-se a imposição de barreiras não tarifárias que viessem a reduzir as importações dos países signatários do acordo a um nível inferior à média dos três últimos anos do comércio. Por outro lado, a aplicação de salvaguardas com validade de três anos foi admitida aos membros do AVT em caso de comprovado dano ou de ameaça à indústria local, por conta das importações crescentes de determinado país (AMARAL, 2008). Dessa forma, as medidas buscavam eliminar paulatinamente as restriçóes ao comércio internacional.

Considerando o período anterior ao AVT e assumindo que determinado país estabeleça uma restrição quantitativa às importações, a intersecção da curva de demanda por importaçôes com o nível de oferta de importação restrita deve definir um patamar de preços mais elevado do que aquele sem a presença das cotas, conforme mostra o Gráfico 1 (FEENSTRA, 2004). A restrição às importações eleva o

\section{GRÁFICO 1}

Imposição de restrição quantitativa de importação

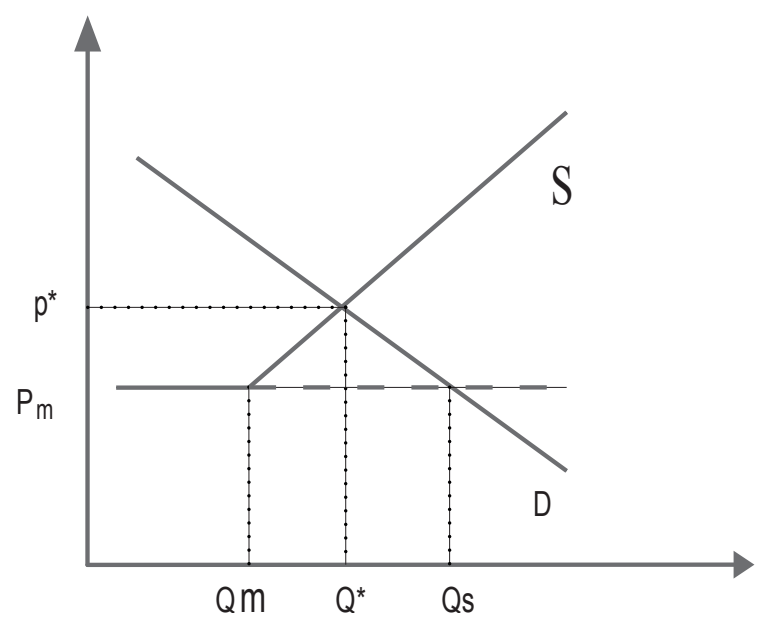

Fonte: Elaboração dos autores.

Nota: As vantagens relativas ao trabalho (oferta e custo) - que motivam os deslocamentos periódicos das unidades produtivas de uma região para outra de mais baixo custo salarial - e as economias de escala permitem admitir uma curva de oferta horizontal até o limite da cota estabelecida pelo país importador. Assim, $Q_{m}$ é a quantidade ofertada por produtores estrangeiros e $\left(Q^{*}-Q_{m}\right)$ a quantidade ofertada pelos produtores nacionais menos competitivos, por hipótese. Nessa situação, o preço e a quantidade de equilíbrio são dados pelo par $\left(\mathrm{Q}^{*}, \mathrm{p}^{*}\right)$. Se as restriçôes às importaçôes são eliminadas, o equilíbrio ocorre em $\left(\mathrm{Q}_{\mathrm{s}}, \mathrm{P}_{\mathrm{m}}\right)$. 
nível de preço no mercado interno, cria melhores condições de concorrência para os produtores domésticos diante dos bens provenientes do exterior e permite a expansão da produção local. Assim, é de se esperar que após o AVT ocorram aumento das importações de bens das duas indústrias e diminuição de preços e da produção doméstica. Em suma, o desvio de comércio deve ser reduzido. ${ }^{2}$

Entretanto, a liberalização gradual proposta pelo AVT contém dois aspecto importantes para os objetivos deste estudo: a maior parte (66\%) da liberação de cotas ocorreu no período final do tratado, depois de 2002; e o cálculo baseado no volume das importaçôes (1990) permitia que as liberações de cotas contemplassem inicialmente itens menos sofisticados, de baixo custo, ou seja, os produtos mais sensíveis à competição foram liberados na última etapa (PROCHNIK, 2003).

Enquanto a eliminação das cotas e a consequente redução da proteção na indústria tornaram-se fontes de preocupação para alguns governos, os países asiáticos despontavam como os maiores beneficiados com o fim do AVT. Na China, em particular, a imensa quantidade de trabalhadores de baixo custo, o parque produtivo moderno - resultado dos elevados investimentos, que auxiliaram a consolidar a indústria de bens de capital local e a baratear os novos investimentos - e a especialização (economias de escala) de algumas cidades costeiras (redução do custo de transportes) em determinados segmentos proporcionaram ao país significativas vantagens competitivas na produção de bens da indústria têxtil e de vestuário (GEREFFI, 2006). Algumas dessas características também são encontradas, em certa medida, em outras naçôes desse continente, especialmente Índia e Vietnã. Assim, sem a devida reação dos competidores, tem fundamento o temor de alguns países em relação aos impactos sobre as suas indústrias nacionais de têxtil e vestuário, ou seja, de um possível deslocamento dessas atividades para o estrangeiro e consequente suprimento da demanda interna por meio de importações.

Como precaução, procurando evitar uma "quebradeira" generalizada de produtores nacionais, alguns acordos foram firmados entre Brasil, EUA e União Europeia e a China, inclusive pela entrada desse último país na OMC. O pacto que vigorou até 2008 também previa a possibilidade de uso de salvaguardas e medidas antidumping se ficasse demonstrado que a China estava vendendo abaixo do custo de produção (NORDAS, 2004; MARTIN, 2007). Nessa situação, algumas medidas de salvaguardas contra a China ainda podem ser utilizadas até 2013.

2 O desvio de comércio referente à presença das cotas deve desaparecer, mas a presença de tarifas de importação (que não são contempladas pelo fim do AVT) gera um componente de desvio de comércio que permanecerá. 


\subsection{0 comércio internacional de bens têxteis e de vestuário e o AVT: 2002-2006}

A Tabela 1 mostra que, a partir de 2002, ano em que são eliminadas as cotas numa proporção de $51 \%$ do volume comercializado em 1990, ocorre uma mudança na taxa de crescimento das exportaçôes mundiais de bens das indústrias têxteis e de vestuário. Se entre 1996 e 2001 o aumento do comércio internacional desses bens foi inferior a 2\%, de 2002 a 2007 houve uma elevação de 38\%. Essa expansão pode ser dividida segundo as duas fases do AVT: aumento de $23 \%$ no período de 2002 a 2005, quando a parcela maior e final das cotas foi eliminada; e crescimento de 15\% de 2005 (início da fase final do AVT) até 2007 (antes da crise internacional).

A partir de 2002 ocorre crescimento das vendas externas da maioria dos países exportadores de bens têxteis e de vestuário, mas parte considerável desse aumento corresponde à China e, em menor proporção, à Índia. A produção chinesa de produtos têxteis e de vestuário cresceu mais de 2,5 vezes $(260 \%$ e $280 \%$, respectivamente) entre 1995 e 2007 . Concomitantemente, a participação desse país no produto mundial elevou-se de $10 \%$, em 1995 , para cerca de $20 \%$, em 2002 , e $40 \%$, em 2006 (Tabela 2). Se considerarmos a produção chinesa e indiana em conjunto, em 2006 os dois países responderam por cerca de 50\% do total mundial (UNIDO, 2010). Nessas circunstâncias, é impossível contestar o deslocamento da produção para a Ásia (Tabela 2).

Segundo Martin (2007), muitos países foram capazes de manter suas exportações de bens têxteis e de vestuário em função dos acordos preferenciais de comércio. Por exemplo, as cotas de importação adotadas pelos EUA contra a China não chegaram a ser totalmente preenchidas. Em outras palavras, as margens largas das restriçôes dos EUA deram vazão ao crescimento da produção (Tabela 2) e das exportações chinesas para esse país. Adicionalmente, alguns exportadores tradicionais de bens têxteis e de vestuário, como Taiwan, Hong Kong e Coreia do Sul, reduziram suas exportações para os EUA após a remoção das cotas, seja por incapacidade desses países de competirem com nações de menores salários, ${ }^{3}$ seja por terem eliminado as exportaçōes por meio de "intermediários". ${ }^{4}$ Esse reposicionamento é parte de uma

3 O deslocamento geográfico da indústria é um fenômeno frequente. Por exemplo, a elevação de salários na China está promovendo a transferência de etapas ou unidades produtivas desse país para o Vietnã, onde o custo da mão de obra é inferior.

4 No passado, procurando burlar as cotas estabelecidas pelos importadores, alguns países realizavam parte de suas exportações por meio de um terceiro país. Por exemplo, Hong Kong foi durante muito tempo um grande exportador mundial, mas parte de "suas exportações" tinha como sustentação a produção subcontratada na China. O aumento das exportações chinesas para os EUA está, muito provavelmente, ligado à eliminação desse "intermediário", desnecessário após o fim das cotas. 
estratégia mais ampla das empresas dos países comparativamente mais desenvolvidos, que parecem migrar para etapas da cadeia produtiva de maior valor agregado, como design e organização da produção, ou procuram competir em segmentos de mercado em que a diferenciação de produto é fundamental (COSTA; ROCHA, 2009).

\section{TABELA 1}

Exportações mundiais de têxteis e de vestuário - 1996-2010

Em bilhōes de US\$ de 2005

\begin{tabular}{rrrrrr}
\hline Anos & US\$ & Anos & US\$ & Anos & US\$ \\
\hline 1996 & 744 & 2001 & 758 & 2006 & 1.040 \\
1997 & 790 & 2002 & 804 & 2007 & 1.112 \\
1998 & 784 & 2003 & 909 & 2008 & 1.048 \\
1999 & 756 & 2004 & 980 & 2009 & 951 \\
2000 & 779 & 2005 & 981 & 2010 & 886 \\
\hline
\end{tabular}

\begin{tabular}{cccc}
\multicolumn{4}{c}{ Crescimento das exportações nas fases do AVT e pós AVT (2005 em diante) em \% } \\
\hline $1996-1998$ & 2,75 & $2003-2004$ & 10,39 \\
$1999-2002$ & 0,71 & $2005-2010$ & $-1,46$ \\
\hline
\end{tabular}

Fonte: COMTRADE - setores (sistema harmonizado): 50 a 63.

Nota: Deflacionados pelos preços ao produtor (manufatura), obtidos na OCDE.

A partir de estatísticas relativas aos EUA entre 2002 e 2005, ou seja, antes e imediatamente após o fim do AVT, Harrigan e Barrows (2009) avaliaram o comportamento dos preços dos bens da indústria têxtil e de vestuário de forma desagregada. Os resultados indicaram que, após o fim do AVT, houve redução nos preços praticados no mercado interno naquelas categorias de bens que estiveram sujeitas ao regime de cotas - destaque para a diminuição de $38 \%$ no preço dos bens importados da China. Em contrapartida, o conjunto de bens sem restrição de cotas não apresentou mudanças significativas nos preços. Ademais, os autores constataram uma mudança da demanda das importaçōes norte-americana para bens relativamente mais baratos. 
O efeito do fim do Acordo sobre têxteis e Vestuários para a indústria brasileira

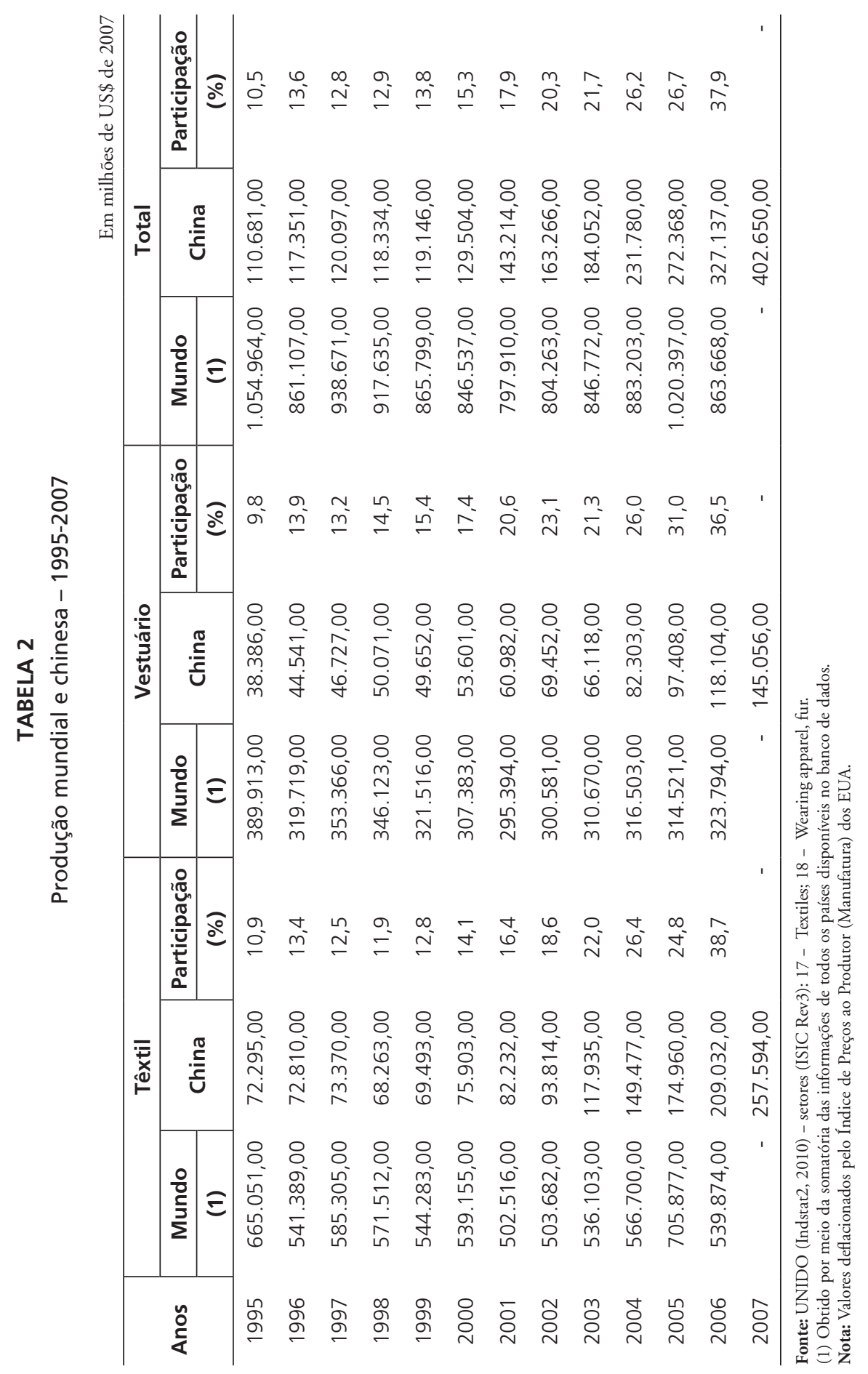


Diogo de Prince Mendonça, Ariene da Silva Salgueiro, Rogério Gomes

\section{Perfil da indústria têxtil e de vestuário do Brasil}

Em 2006, o Brasil foi o $6^{\circ}$ maior produtor mundial de têxteis e vestuários, mas figurou apenas no $46^{\circ}$ e no $43^{\circ}$ lugares entre os maiores exportadores e importadores, respectivamente. Em outras palavras, o mercado interno absorve grande parte da produção doméstica. Não obstante, entre 1995 e 2007, apesar do aumento do consumo per capita, a produção per capita de bens têxteis e de vestuário teve leve redução ${ }^{5} \mathrm{e}$ as importações vêm suprindo parcela da demanda interna (COSTA; ROCHA, 2009).

Os dados da Tabela 3 mostram que no período de 1995 a 2007 a produção têxtil cresceu pouco acima de $2 \%$ e a de vestuário diminuiu cerca $15 \%$. Se considerarmos que a indústria de vestuário requer maior número de empregados, entende-se porque ela foi mais fortemente afetada pela concorrência externa, especialmente de origem asiática.

A posição brasileira no mercado internacional de bens têxteis e de vestuário também vem se deteriorando. Se em 1997 a participação do Brasil no comércio mundial desses produtos representava $0,7 \%$ do total, em 2007 reduziu-se para 0,3\%, um movimento oposto ao do consumo global no mesmo período. Entre 1996 e 2008, apesar dos dois períodos de valorização cambial (1994 a 1998 e o iniciado em 2004), as exportações brasileiras de bens das duas indústrias mantiveram tendência suave de crescimento, em grande medida devido à expansão da demanda mundial. Por outro lado, o relativo declínio das importações até 2002 foi revertido com a posterior apreciação da moeda nacional e, também, com o fim dos acordos AVT (2005-2006) e salvaguardas posteriores (2008) (Gráfico 2). No conjunto, os movimentos desses dois fluxos resultaram em superávits comerciais por alguns anos, mas, a partir de 2006, os déficits comerciais reapareceram, superando aqueles alcançados no período de valorização cambial do pós-Plano Real. Em resumo, câmbio apreciado e aumento da desregulamentação do comércio exterior promovem impactos negativos sobre o comércio exterior das indústrias têxteis e de vestuário nacional (COSTA, ROCHA, 2009).

Até 2005, os EUA eram o principal destino das exportações brasileiras de têxteis e vestuários. Aparentemente, essas vendas foram afetadas pelo término do AVT, pois, concomitantemente, aumentou a participação da China como origem das importações estadunidenses. Alternativamente, o Brasil intensificou suas relações com os países da América Latina.

5 A produção nacional diminuiu em cerca de 7\%, entre 1995 e 2007 (Tabela 3). Certamente esta redução não está atrelada apenas ao AVT. No período há outros fatores muito relevantes, principalmente a abertura comercial e a valorização da moeda nacional. 
O efeito do fim do Acordo sobre têxteis e Vestuários para a indústria brasileira

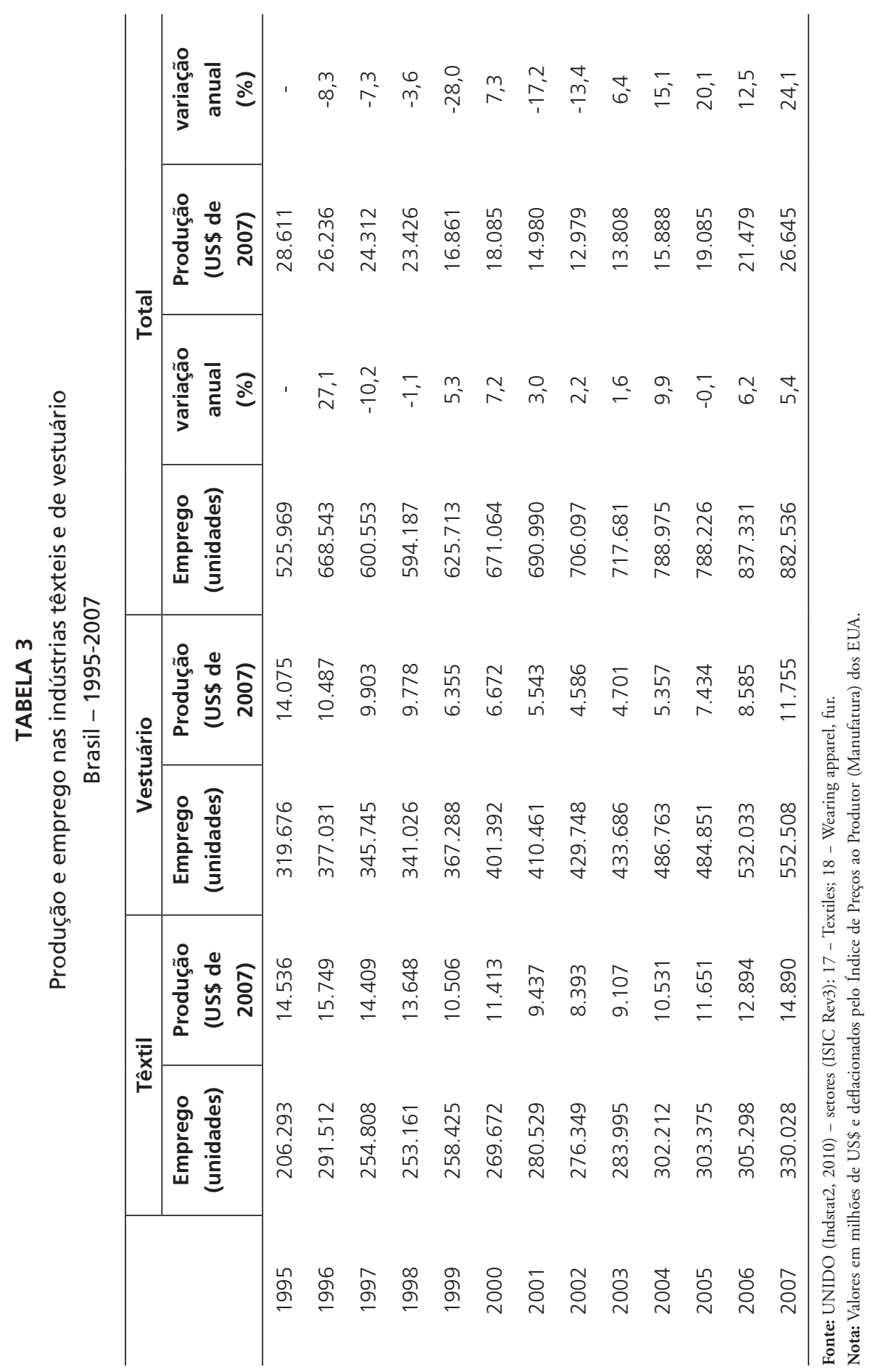


As importações brasileiras de têxteis e vestuários com origem na China cresceram 212\%, entre 2005 e 2007, e 53\%, no período de 2008 a 2010. Essas taxas explicam o aumento da participação da China nas importaçôes desses bens de 20\% para 36\%, entre 2005 e 2010. Assim, a indicação é de que a China não apenas substitui o Brasil em parte das suas vendas externas, mas também supre uma parcela do mercado interno antes ocupada pela produção nacional.

No período imediatamente após o fim do acordo AVT, a produção doméstica de bens têxteis e de vestuário manteve-se relativamente constante, apesar do crescimento das importaçôes. No entanto, o encerramento do memorando de entendimento entre Brasil e China em 2008, que ainda limitava quantitativamente as importaçôes chinesas, parece ser responsável por parcela significativa do efeito negativo dessas compras sobre a indústria nacional (Gráfico 2).

\section{GRÁFICO 2}

Balanço comercial de produtos têxteis e de vestuários Brasil - 1996-2010

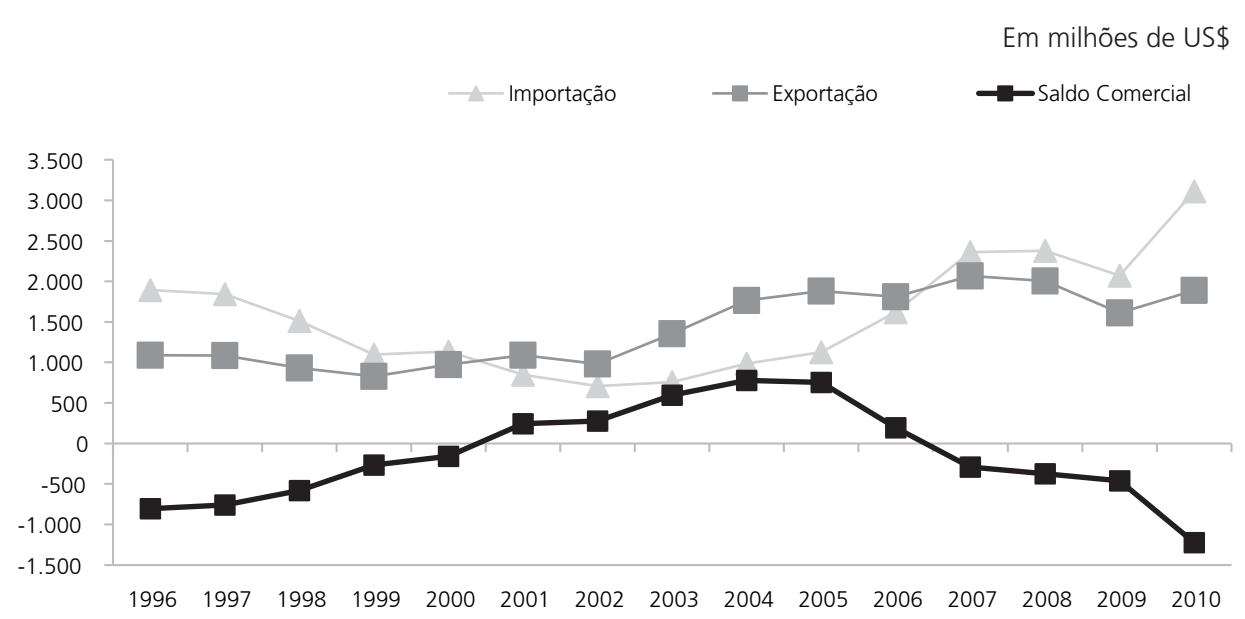

Fonte: Fundação Centro de Estudos do Comércio Exterior (Funcex).

Os principais produtos têxteis e de vestuário brasileiros de exportação são as fibras naturais, enquanto os importados concentram-se em filamentos de poliéster e tecidos sintéticos - uma característica que configura certa divisão internacional do trabalho. Assim, há um déficit comercial em bens produzidos a partir de fibras químicas, mas a competitividade do algodão nacional garante um superávit comercial em produtos de fibras naturais. Esse aspecto positivo da indústria nacional é 
sustentado pela presença de empresas competitivas internacionalmente, que atuam nesse segmento de mercado (PROCHNICK, 2003).

Uma das características marcantes dessa indústria em âmbito global é a presença de polos regionais de produção. No Brasil, está instalado um dos polos mais avançados da América Latina, localizado em Santa Catarina (COSTA, ROCHA, 2009). Neste estudo, esse Estado é muito relevante em virtude da forte concentração de empresas na amostra avaliada.

A indústria têxtil e de vestuário brasileira é formada, majoritariamente, por pequenas e médias empresas. Para Prochnick (2003), um dos problemas da cadeia têxtil e de confecção está na "grande massa de empresas ineficientes" e, em geral, pequenas. Os investimentos na indústria brasileira de têxteis e de vestuário estão concentrados na aquisição de máquinas e equipamentos. Entretanto, segundo Costa e Rocha (2009) e Gorini (2000), houve um envelhecimento do parque industrial nos anos 2000. Enquanto entre 1990 e 1999 os investimentos da ordem de US\$ 4 bilhões reduziram a idade média dos equipamentos, entre 2000 e 2007 as inversōes de US\$ 4,5 bilhôes foram insuficientes para evitar o envelhecimento do parque produtivo. Assim, em 2007 a idade média dos equipamentos voltou aos níveis de 1990. Em suma, muito provavelmente aumentou a assimetria tecnológica da indústria.

Se a abertura do mercado doméstico brasileiro e os investimentos realizados por conta disso foram um incentivo à diminuição da idade média do parque industrial na década de 1990, a desvalorização cambial e o fim do AVT não parecem ter sido um estímulo nos anos 2000. Nesse sentido, o cenário da indústria esboçado anteriormente não é propriamente uma surpresa em virtude da redução da competitividade da indústria brasileira diante dos concorrentes externos.

Apesar destas perspectivas pouco alentadoras, as indústrias têxteis e de vestuário ainda mantêm grande importância na economia brasileira. Em 1999, as duas atividades em conjunto respondiam por $14 \%$ do total de empregos da indústria de transformação brasileira, proporção que alcançou 17\%, em 2007.

\section{Modelo de eficiência e fronteira de produção estocástica}

O procedimento paramétrico adotado neste estudo para avaliar a eficiência técnica e a produtividade dos fatores foi estimar a fronteira de produção estocástica. Esse método parte de uma fronteira de produção $f(x)$ que representa o máximo de produto possível a partir da melhor combinação de fatores e um dado nível de insumos. As 
empresas operam na fronteira de produção ou abaixo dela, sendo definidas, respectivamente, como tecnicamente eficientes e ineficientes.

Uma formulação apropriada seria estimar a seguinte equação:

$$
y_{i t}=f\left(x_{i t}\right)=\exp \left(\beta x_{i t}+v_{i t}-u_{i t}\right)
$$

em que $y_{i t}$ é a variável dependente, $x_{i t}$ corresponde aos insumos, $v_{i t}$ representa o termo de erro aleatório e $-u_{i t}$ refere-se ao componente de ineficiência (quanto a produção da empresa encontra-se abaixo da fronteira de produção). O termo $v_{i t}$ é normalmente distribuído com média zero e variância $\sigma_{v}^{2}$. A ineficiência $u_{i t}$ é independente de $v_{i t}$ e segue uma distribuição normal com média $m_{i t}$ e variância $\sigma_{v}^{2}$, tal que $u_{i t} \geq 0$. Ademais, supõe-se que o vetor $\beta$ seja igual para todas as empresas, significando que elas utilizam a mesma tecnologia de produção.

A eficiência técnica (TE) da empresa foi obtida pela divisão do produto observado (y) em relação à função de produção:

$$
T E_{i t}=\frac{y_{i t}}{\exp \left(\beta x_{i t}+v_{i t}\right)}=\frac{\exp \left(\beta x_{i t}+v_{i t}-u_{i t}\right)}{\exp \left(\beta x_{i t}+v_{i t}\right)}=\exp \left(-u_{i t}\right)
$$

Assim, TE é dado por um intervalo de valores entre 0 e 1 (COELLI et al., 2005).

O método utilizado para estimar os parâmetros é a função de máxima verossimilhança, necessitando assumir uma distribuição para o termo de ineficiência. Segundo Greene (2007), a distribuição meio-normal (e suas variantes) tem sido uma especificação frequente nos estudos recentes.

O modelo empregado neste estudo baseou-se em Battese e Coelli (1995). Esse modelo estima a fronteira de produção estocástica obtendo a ineficiência simultaneamente com uma função de variáveis específicas à empresa $\left(z_{i t}\right)$. Em outras palavras, as equações a seguir são estimadas simultaneamente:

$$
\begin{aligned}
& y_{i t}=\exp \left(\beta x_{i t}+v_{i t}-u_{i t}\right) \\
& m_{i t}=\delta z_{i t}+\omega_{i t}
\end{aligned}
$$

em que $\omega_{i t}$ é o termo de erro e tem distribuição normal com média zero e variância $\sigma_{\omega}^{2}$.

A parametrização de Battese e Corra (1977) adotada no trabalho utiliza $\sigma^{2}=\sigma_{v}^{2}+\sigma_{u}^{2}$ e $\gamma=\frac{\sigma_{u}^{2}}{\left(\sigma_{v}^{2}+\sigma_{u}^{2}\right)}$. Essa parametrização permite testar se a fronteira de 
produção estocástica é adequada. Se a hipótese nula de $\gamma=0$ for aceita, $\sigma_{u}^{2}=0$, o termo de ineficiência deve ser removido do modelo. Assim, a estimação por mínimos quadrados ordinários permite obter parâmetros consistentes. Por outro lado, caso a hipótese nula seja rejeitada, a fronteira de produção estocástica é adequada e o método da fronteira de produção estocástica permite a obtenção dos índices de eficiência técnica para as empresas. Além disso, os resultados obtidos a partir desse método fornecem também a produtividade total dos fatores, como explicado na próxima subseção.

\subsection{0 índice de Malmqüist de produtividade total dos fatores}

Este estudo busca avaliar o comportamento da eficiência e da produtividade das empresas têxteis na amostra. Uma das formas de efetuar essa medida de produtividade é por meio da produtividade total dos fatores (PTF), que considera todos os fatores de produção. Aqui se emprega o índice de Malmqüist, que permite desmembrar a PTF em dois componentes para caracterizar as origens da mudança na produtividade: a variação da produtividade em mudanças tecnológicas (MT) e de eficiência (ME).

$\mathrm{O}$ índice de Malmqüist produto-orientado mensura a mudança na PTF pela razão entre a distância (função $d$ ) de dois pontos, um no período $t$ e outro no período $s(t>s)$. A função $d$ é definida como a menor distância entre o produto da firma e a fronteira de produção estimada para aquele determinado período. ${ }^{6}$ Dessa maneira, o índice de Malmquist baseia-se no termo $u$ do modelo. Considerando a mesma tecnologia, o índice pode ser calculado para o período de referência $t$ por:

$$
m_{0}^{t}\left(y_{s}, x_{s}, y_{t}, x_{t}\right)=\frac{d_{0}^{t}\left(y_{t}, x_{t}\right)}{d_{0}^{t}\left(y_{s}, x_{s}\right)}
$$

em que $\mathrm{x}_{s}, \mathrm{x}_{\mathrm{t}}, \mathrm{y}_{\mathrm{s}}$ e $\mathrm{y}_{\mathrm{t}}$ são, respectivamente, os vetores de insumos e produtos para os períodos $s$ e $t$.

Se a referência for a tecnologia do período $s$, o índice será obtido por:

$$
m_{0}^{s}\left(y_{s}, x_{s}, y_{t}, x_{t}\right)=\frac{d_{0}^{s}\left(y_{t}, x_{t}\right)}{d_{0}^{s}\left(y_{s}, x_{s}\right)}
$$

6 Em outros termos, a função $d$ é a menor distância do ponto que considera os vetores de insumos e de produto à fronteira de produção. Outra maneira seria determinar que a distância é obtida ao minimizar a eficiência técnica (SHEPHARD, 1970). 
A função distância produto-orientado mensura no eixo do produto a distância entre os produtos observado e potencial. Considerando uma determinada quantidade de insumos, o produto potencial é o ponto sobre a curva de fronteira de produção, a qual está relacionada com a firma de maior eficiência técnica naquele período.

Para evitar uma escolha arbitrária entre as tecnologias do período $s$ ou $t$, define-se o índice de Malmqüist pela média geométrica das funções distância para a tecnologia dos períodos $s$ e $t$ :

$$
m_{0}\left(y_{s}, x_{s}, y_{t}, x_{t}\right)=\left[\frac{d_{0}^{s}\left(y_{t}, x_{t}\right)}{d_{0}^{s}\left(y_{s}, x_{s}\right)} \cdot \frac{d_{0}^{t}\left(y_{t}, x_{t}\right)}{d_{0}^{t}\left(y_{s}, x_{s}\right)}\right]
$$

Se rearranjada, a equação anterior resulta que o índice de Malmqüist é igual à multiplicação da variação de ME (primeiro termo) e de MT (termo entre colchetes):

$$
m_{0}\left(y_{s}, x_{s}, y_{t}, x_{t}\right)=\frac{d_{0}^{t}\left(y_{t}, x_{t}\right)}{d_{0}^{s}\left(y_{s}, x_{s}\right)}\left[\frac{d_{0}^{s}\left(y_{t}, x_{t}\right)}{d_{0}^{t}\left(y_{t}, x_{t}\right)} \cdot \frac{d_{0}^{s}\left(y_{s}, x_{s}\right)}{d_{0}^{t}\left(y_{s}, x_{s}\right)}\right]
$$

O componente ME permite visualizar se há aumento, manutenção ou diminuição da eficiência técnica no tempo quando o primeiro termo da equação acima for, respectivamente, maior, igual e menor do que a unidade. ${ }^{7}$ Analogamente, o termo MT indica se há aumento, manutenção ou redução do progresso tecnológico quando o segundo termo for, respectivamente, maior, igual e menor do que a unidade.

Para elucidar o cálculo de MT e ME, o Gráfico 3 apresenta as funções de distância orientada pelo produto. Pela figura, teríamos que $d_{0}^{s}\left(y_{s}, x_{s}\right)=\frac{0 a}{0 b}, d_{0}^{t}\left(y_{t}, x_{t}\right)=\frac{0 d}{0 e}$, $d_{0}^{t}\left(y_{s}, x_{s}\right)=\frac{0 a}{0 f} \quad$ e $d_{0}^{s}\left(y_{t}, x_{t}\right)=\frac{0 d}{0 c}$. Assim, substituindo essas relações em (8), teremos:

$$
M T=\left[\frac{0 e}{0 c} \cdot \frac{0 f}{0 b}\right]^{1 / 2}
$$

7 Como $\quad d_{0}^{s}\left(y_{s}, x_{s}\right)=T E_{i s}$ e $d_{0}^{s}\left(y_{s}, x_{s}\right)=T E_{i s}$ podemos reescrever o índice como ${ }^{M E}=\frac{T E_{t s}}{T E_{s}}$ 
$M E=\left[\frac{0 d}{0 e} \cdot \frac{0 a}{0 b}\right]$

Em outras palavras, a distância $0 d$ seria dada pela combinação de insumos e de produto no período $t$ e a diferença entre $0 d$ e $0 e$ seria o termo de ineficiência, baseando-se na tecnologia do período $t$. Os termos $0 e$ e $0 f$ são obtidos, respectivamente, pelos pontos sob a fronteira de produção estimada no período $t$ quando os vetores de insumos são $x_{s}$ e $x_{t}$, o caso de plena eficiência. As demais distâncias são obtidas seguindo esse raciocínio.

\section{GRÁFICO 3}

Funções de distância orientada pelo produto

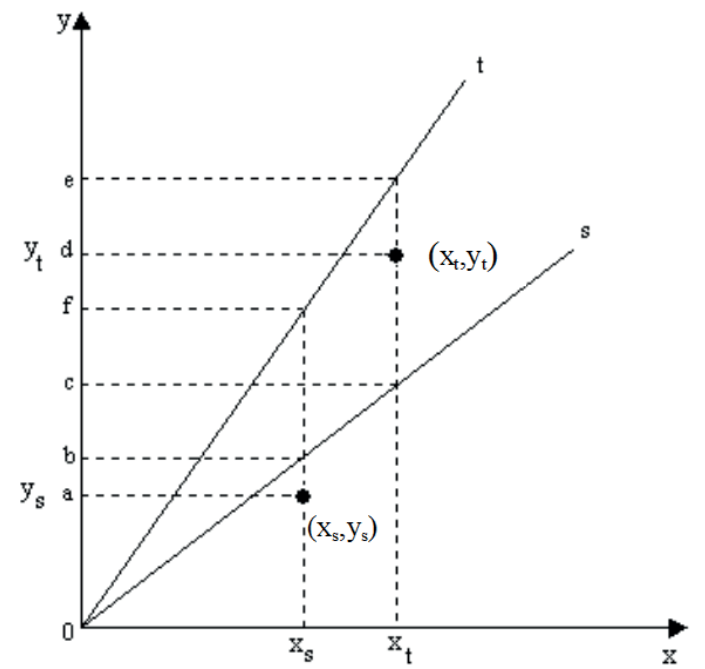

Fonte: Elaboração dos autores.

Neste estudo, o cálculo das funções de distância será obtido a partir dos termos de ineficiência e da fronteira de produção estimada. A partir desses coeficientes, discutiremos sobre o índice de Malmqüist e os seus dois componentes - ME e MT. A seção a seguir discorre sobre os dados utilizados e a validade do modelo aplicado neste trabalho. 
Diogo de Prince Mendonça, Ariene da Silva Salgueiro, Rogério Gomes

\subsection{As empresas, os dados utilizados e especificação da função de produção}

As informaçōes utilizadas neste estudo foram obtidas dos demonstrativos financeiros disponíveis na página da BM\&FBovespa. Assim, como a amostra está circunscrita às empresas listadas na bolsa de valores, classificadas setorialmente nas categorias "Fios e tecidos" e "Vestuário", ela está restrita às grandes empresas da indústria do país.

As contas utilizadas foram o "Imobilizado" do Ativo e "Salários a pagar" do Passivo para representar, respectivamente, os fatores capital (k) e trabalho (l). Os insumos considerados foram o estoque de capital e o pagamento ao estoque de trabalho (salário). Esse é um tratamento assimétrico dos insumos por conta da dificuldade de acesso aos dados de estoque de trabalhadores e, portanto, pode influenciar os resultados pela valorização do salário no período analisado. Um aumento no salário por trabalhador (regra para o período) indicaria uma elevação na quantidade utilizada de fator trabalho, mesmo sem mudança no montante produzido. Isso significa que potencialmente o fator trabalho está superavaliado no presente estudo.

A variável de produto (y) da empresa baseou-se na "receita bruta" da Demonstração do Resultado - estas três variáveis medidas em mil reais. A variável idade (anos) foi obtida pela data de fundação da empresa, disponível no Relatório da Administração ou no seu site. Ademais, a conta estoques do ativo (mil reais), denominada I, é considerada um indicador de ineficiência devido aos custos financeiros associados.

Da amostra inicial composta pelos critérios mencionados, foram mantidas apenas as empresas que declararam "Salários a pagar" no Passivo. Assim, a amostra final contempla 13 empresas das indústrias têxteis e de vestuário com informações para o período de 1997 a 2008; são elas: Buettner (SC-T), Cataguases (MG-T), Schlosser (SC-T), Renaux (SC-T), Karsten (SC-T), Nova América (RJ-T), Pettenati (RS-T), Teka (SC-T), Renauxview (SC-T), Vicunha (CE-T), Ferreira Guimarães (RJ-T), Botucatu (SP-V) e Hering (SC-V). A amostra caracteriza-se por estar concentrada em empresas da indústria têxtil (11) e com sede (7) em Santa Catarina. Em função dessa última característica, realizamos um esforço adicional e examinamos também as diferenças entre as empresas têxteis de Santa Catarina e as dos demais Estados.

O método utilizado neste estudo é a estimação de fronteira de produção estocástica para um painel desbalanceado. Emprega-se a transformação logarítmica para todas as variáveis incluídas nos modelos. A forma funcional aqui adotada é a de uma função translog, que impõe restrições sobre as elasticidades dos fatores da função de produção. Assim, a equação estimada será do tipo: 
$y_{i t}=\beta_{0}+\beta_{k} k_{i t}+\beta_{l} l_{i t}+\beta_{k l} k_{i t} l_{i t}+\beta_{k k} k_{i t}^{2}+\beta_{l l} l_{i t}^{2}+\beta_{t k} t k_{i t}+\beta_{t l} t l_{i t}+\beta_{t} t$

$+\beta_{t t} t^{2}+v_{i t}-u_{i t}$

em que $i=1, \ldots, 13$ e $t=1, \ldots, 12$.

O efeito da ineficiência técnica $\left(u_{i t}\right)$ segue uma distribuição normal $N\left(m_{i t}, \sigma_{u}^{2}\right)$ e é modelado pela equação:

$$
m_{i t}=\delta_{0}+\delta_{1} I_{i t}+\delta_{2} \text { idade }_{i t}+\delta_{3} I_{i t}^{2}+\delta_{4} i d a d e_{i t}^{2}+\sum_{j=1}^{12} \delta_{j+4} D_{j}+\omega_{i t}
$$

no qual o penúltimo termo contabiliza as dummies de efeito fixo $\left(D_{j}\right)$ das empresas para explicar o efeito de ineficiência. ${ }^{8}$ A escolha das variáveis explicativas na equação do termo de ineficiência baseou-se parcialmente em Bhandari e Maiti (2007). A interpretação sobre o efeito do fim do acordo AVT será baseada no comportamento do índice de Malmqüist e de seus dois componentes para avaliar a reação dos produtores nacionais à concorrência estrangeira.

\section{Resultados}

Nesta seção expõem-se os resultados para a estimação da fronteira de produção e o cálculo do índice de Malmqüist e os seus componentes. A Tabela 4 apresenta os resultados do modelo de fronteira de produção estocástica. Observa-se que, em virtude da significância estatística individual dos coeficientes associados à variável tempo e de suas interações com os fatores de produção, houve progresso tecnológico para as empresas da amostra no período examinado. Ainda de forma conjunta foi testada a significância dos coeficientes associados ao progresso tecnológico (Tabela 5, teste número dois). A rejeição da hipótese nula é outra evidência de que há progresso tecnológico. Além disso, não há indicação de que os fatores trabalho e capital sejam substitutos, pois o sinal positivo do coeficiente associado a $\mathrm{K}^{*} \mathrm{~L}$ aponta que os dois fatores são complementares (Tabela 4).

Em relação à equação com o termo de ineficiência como variável dependente, encontramos que a ineficiência (menor) da empresa mantém relação inversa com a sua idade (maior), resultado que corrobora com Lall e Rodrigo (2001). Para os autores, esses resultados se justificam, pois as empresas mais antigas usufruem de acesso facilitado ao sistema financeiro, formas de organização do processo produtivo

8 As variáveis do trabalho foram todas transformadas para logaritmo natural. 
e de gestão do trabalho aperfeiçoadas, redes de fornecedores, distribuição e comercialização mais bem estabelecidas, etc. No entanto, essa avaliação contrapõe-se ao obtido por Bhandari e Maiti (2007) para o setor têxtil indiano.

TABELA 4

Fronteira de produção estocástica e a equação de ineficiência

\begin{tabular}{|c|c|}
\hline & Variável de dependente: y \\
\hline & Coeficiente \\
\hline c & $-0,12 * \star \star$ \\
\hline K & $1,41 * \star \star$ \\
\hline $\mathrm{L}$ & $0,11 * \star *$ \\
\hline$K * L$ & $0,01 * *$ \\
\hline$K^{2}$ & $-0,08 * * *$ \\
\hline$L^{2}$ & $-0,01 * * *$ \\
\hline tK & $0,01 * * *$ \\
\hline $\mathrm{tL}$ & $-0,01 * * *$ \\
\hline $\mathrm{t}$ & $0,15^{\star * *}$ \\
\hline \multirow[t]{4}{*}{$t^{2}$} & $-0,02 * * *$ \\
\hline & Modelo de ineficiência (1) \\
\hline & Variável dependente: u \\
\hline & Coeficiente \\
\hline c & $-0,48$ \\
\hline I & $1,15 * * *$ \\
\hline idade & $-1,14^{*}$ \\
\hline $1^{2}$ & $-0,07 * * *$ \\
\hline idade $^{2}$ & 0,09 \\
\hline Efeitos fixos & Sim \\
\hline$\sigma^{2}$ & $0,56 * * *$ \\
\hline$\gamma$ & $0,99 * * *$ \\
\hline Log verossimilhança & $-45,68$ \\
\hline Eficiência média & 0,5165 \\
\hline Número de iterações & 45 \\
\hline Teste LR & 205,44 \\
\hline
\end{tabular}

Fonte: BM\&FBovespa. Elaboração dos autores.

(1) Os efeitos fixos estão presentes no modelo de ineficiência, mas não são apresentados na tabela.

Nota: ${ }^{* * *},{ }^{* *} \mathrm{e}^{*}$ indicam, respectivamente, níveis de significância de $1 \%, 5 \%$ e $10 \%$. 
Uma segunda variável explicativa para o termo de ineficiência corresponde ao estoque de bens e insumos. $\mathrm{O}$ resultado obtido foi que um maior estoque leva ao aumento da ineficiência das empresas. Ademais, é necessário ressaltar que outras duas variáveis explicativas do modelo de ineficiência foram retiradas pela insignificância estatística associada aos coeficientes: a interação entre tamanho do estoque e idade; e uma dummy para captar o efeito diferenciado das empresas têxteis com sede em Santa Catarina. Assim, o "efeito Santa Catarina" para as empresas têxteis será analisado por meio dos indicadores de elasticidade dos insumos e do índice de Malmqüist.

A adequação do modelo de fronteira estocástica foi verificada pelo teste LR unicaudal $^{9}$ e o teste sobre o parâmetro $\gamma$ (Tabela 4). A estimação da fronteira de produção com o termo de ineficiência foi válida para ambos os testes, em que $\gamma$ é estatisticamente diferente de zero. Assim, a estimação da fronteira de produção por mínimos quadrados ordinários não é razoável neste caso.

Os demais testes para verificar se a forma funcional estimada é adequada também são apresentados na Tabela 5 . O primeiro teste apresenta como hipótese nula a forma funcional da função de produção com a especificação Cobb-Douglas. ${ }^{10} \mathrm{~A}$ rejeição da hipótese nula indica que a função translog é preferível.

TABELA 5

Testes de razão de verossimilhança

\begin{tabular}{c|c|c|c|c}
\hline Teste & Hipótese nula $\left(\mathrm{H}_{0}\right)$ & $\begin{array}{c}\text { Estatística } \\
\text { LR }\left(\chi^{2}\right)\end{array}$ & g.1. & Resultado \\
\hline 1 & $\beta_{k l}=\beta_{k k}=\beta_{l l}=\mathbf{O}$ & 16,51 & 3 & Rejeita $\mathrm{H}_{0}$ \\
2 & $\beta_{t k}=\beta_{t l}=\beta_{t}=\beta_{t t}=0$ & 101,44 & 4 & Rejeita $\mathrm{H}_{0}$ \\
3 & $\delta_{1}=\delta_{2}=\ldots=\delta_{16}=\mathbf{O}$ & 144,02 & 16 & Rejeita $\mathrm{H}_{0}$ \\
4 & $\delta_{5}=\ldots=\delta_{16}=0$ & 85,11 & 12 & Rejeita $\mathrm{H}_{0}$ \\
\hline
\end{tabular}

Fonte: BM\&FBovespa. Elaboração dos autores.

O terceiro teste (Tabela 5) verifica se os coeficientes do modelo de ineficiência são conjuntamente nulos sob a hipótese nula. $\mathrm{O}$ teste indica rejeição da hipótese

9 O teste LR unicaudal testa se o ajuste do modelo é superior àquele em que todos os parâmetros do modelo de ineficiência são iguais a zero. A tabela de valores críticos desse teste encontra-se em Kodde e Palm (1986).

10 A especificação Cobb-Douglas restringe os parâmetros cruzados ao quadrado dos insumos da função de produção 
nula, de modo que o montante de estoque da empresa, sua idade e seus efeitos fixos explicam o termo de ineficiência das firmas da amostra. Por fim, o quarto teste estabelece como hipótese nula que todos os efeitos fixos são nulos. A rejeição da hipótese nula indica que as especificidades das empresas explicam parcela da ineficiência.

$\mathrm{Na}$ Tabela 6, as elasticidades médias dos insumos e o efeito do progresso tecnológico foram estimados diferenciando-se as empresas por sedes: as estabelecidas em Santa Catarina e as dos demais Estados. Comparativamente, o incremento do fator trabalho aumentaria o produto daquelas localizadas em Santa Catarina, enquanto o fator capital adicionaria produto às empresas sediadas nos demais Estados brasileiros. Entretanto, como o fator trabalho pode estar superavaliado, isso significaria um efeito menor do fator trabalho do que o estimado na Tabela 6. Assim, a elasticidade média estimada do fator trabalho pode ser vista como um limite superior para a estimativa corretamente mensurada pelo estoque do fator trabalho. Além disso, o incremento percentual na produção derivado do progresso tecnológico tem sido maior para as empresas estabelecidas em Santa Catarina do que para as dos demais Estados. Essa avaliação é complementada a seguir pela decomposição do índice de Malmqüist.

TABELA 6

Elasticidades médias do produto têxtil em relação aos fatores trabalho, capital e progresso tecnológico de 1997 a 2008

\begin{tabular}{ccc}
\hline & Demais Estados & Santa Catarina \\
\hline L & 0,0514 & 0,0678 \\
K & 0,6286 & 0,6140 \\
$\mathrm{t}$ & 0,0713 & 0,0786 \\
\hline
\end{tabular}

Fonte: BM\&FBovespa. Elaboração dos autores.

Como mencionado na seção 4.1, o índice de Malmqüist permite desmembrar a produtividade total dos fatores em seus dois componentes: ME (eficiência técnica); e MT (progresso tecnológico). O primeiro avalia se as empresas estão se aproximando da fronteira de produção, enquanto o segundo indica o movimento da fronteira de produção ao longo do tempo. Para todos os indicadores, valores superiores e inferiores a 1 significam, respectivamente, crescimento e redução do índice ou subíndice. Os resultados encontrados para cada um deles são apresentados na Tabela 7. 
O efeito do fim do Acordo sobre têxteis e Vestuários para a indústria brasileira

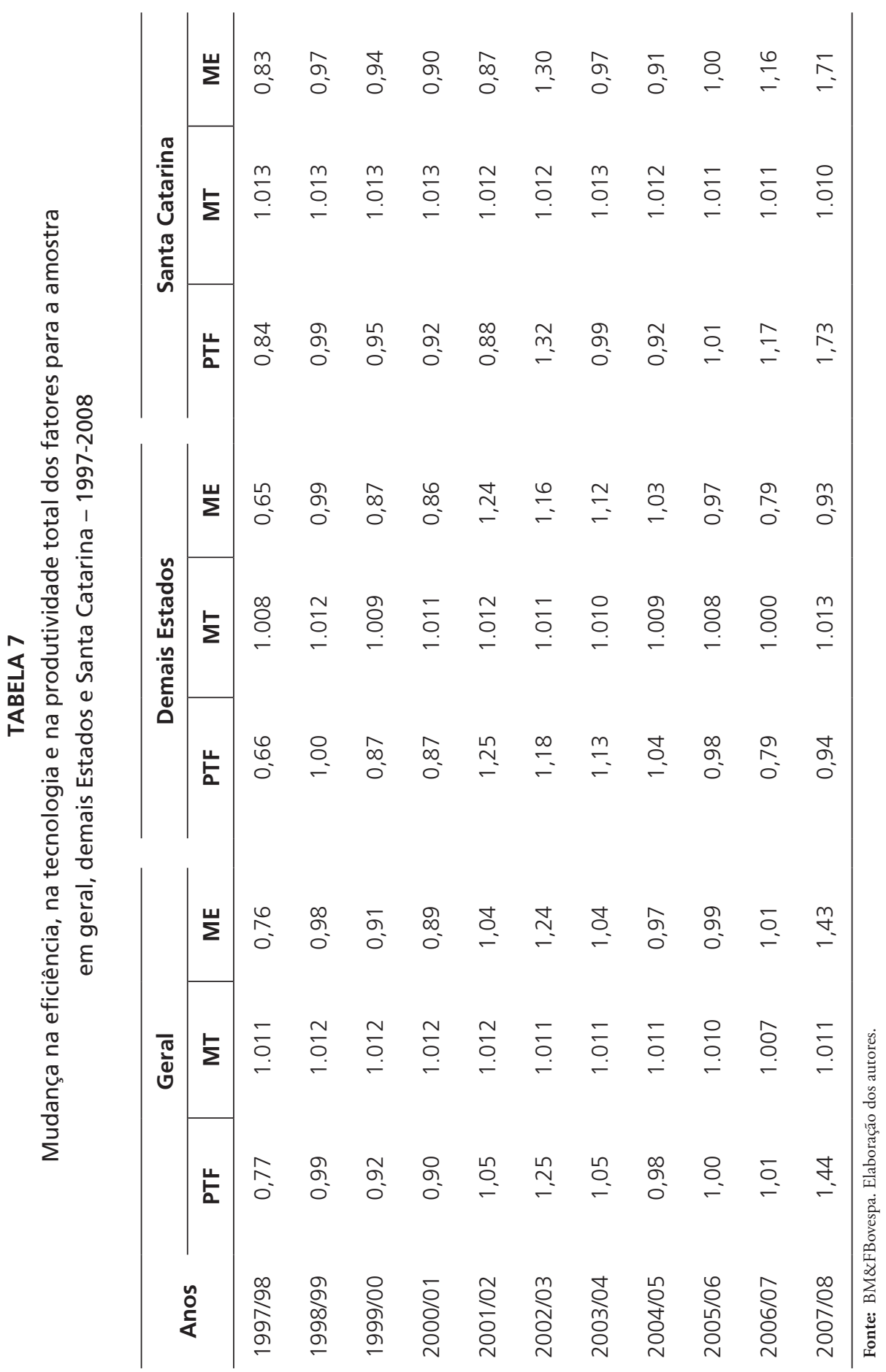


Diogo de Prince Mendonça, Ariene da Silva Salgueiro, Rogério Gomes

Em termos gerais, houve redução da produtividade total dos fatores das empresas da amostra até 2001 e crescimento a partir de 2002. O comportamento da produtividade total dos fatores foi conduzido pela mudança de eficiência, pois houve progresso tecnológico em todo o período, indicando que a fronteira de produção evoluiu. A mudança de eficiência indica que as empresas se afastaram da fronteira de 1998 até 2001, se aproximaram dela até 2004, voltaram a se distanciar justamente nos anos iniciais do fim do AVT (2005-2006) e reaproximaram-se novamente em 2007 e 2008.

A opção de estudar o comportamento da produtividade total de fatores e seus componentes diferenciando as empresas sediadas em Santa Catarina e nos demais Estados explica os índices (6 colunas) à direita da Tabela 7. Aquelas sediadas nos "demais Estados" apresentaram aumento na produtividade entre 2002 e 2005, enquanto as de Santa Catarina tiveram suas produtividades reduzidas (exceto em 2003). No entanto, há uma mudança nesse cenário a partir de 2006 (em 2005 foi extinto o AVT), quando a produtividade das empresas de Santa Catarina se expande e ocorre certa retração para aquelas dos "demais Estados". Essas circunstâncias indicam que o fim do AVT pode ter motivado uma reação das firmas de Santa Catarina, mas, também, um aparente aumento da fragilidade competitiva das companhias dos "demais Estados".

O último ponto de análise refere-se à eficiência das empresas. Em termos gerais, o Gráfico 4 mostra uma tendência de queda da eficiência das empresas da amostra, revertida parcialmente em 2008. Para a amostra, um teste de médias para os níveis de eficiência em 2004 e 2006 (anos anterior e posterior ao fim do AVT) indica que a hipótese nula de igualdade do nível de eficiência não pode ser rejeitada. Entretanto, o teste unicaudal apresenta p-valor de 6,86\% (a 10\% de significância estatística), ou seja, favorecendo a hipótese alternativa de que a eficiência em 2004 foi maior do que a de 2006. ${ }^{11}$

Ao se separarem as empresas por Estado, há um comportamento consideravelmente distinto. Durante o período analisado (1997 e 2008), apenas entre 2004 e 2006 (fase final do AVT) as firmas dos "demais Estados" são mais eficientes que as de Santa Catarina. No entanto, essas últimas caracterizam-se por apresentar uma queda considerável na eficiência, que passou de 0,74 em 1997 para 0,39 em 2005, quando ocorre uma reação e a eficiência aumenta para 0,62, em 2008.

Em síntese, as empresas de Santa Catarina foram mais eficientes e parece haver uma tendência de recuperação da eficiência dessas firmas após o fim do AVT. Por outro lado, aquelas instaladas nos demais Estados apresentam uma contínua queda

11 Uma ressalva sobre tal resultado é o baixo número de graus de liberdade. Alternativamente, o teste de médias indicou que as eficiências em 2004 e em 2007 (ou em 2008) não apresentaram diferenças estatísticas. 
de eficiência após o fim do AVT. Assim, as evidências obtidas neste estudo reforçam o papel do polo regional de produção em Santa Catarina para o Brasil.

\section{GRÁFICO 4}

Eficiência média calculada para a amostra

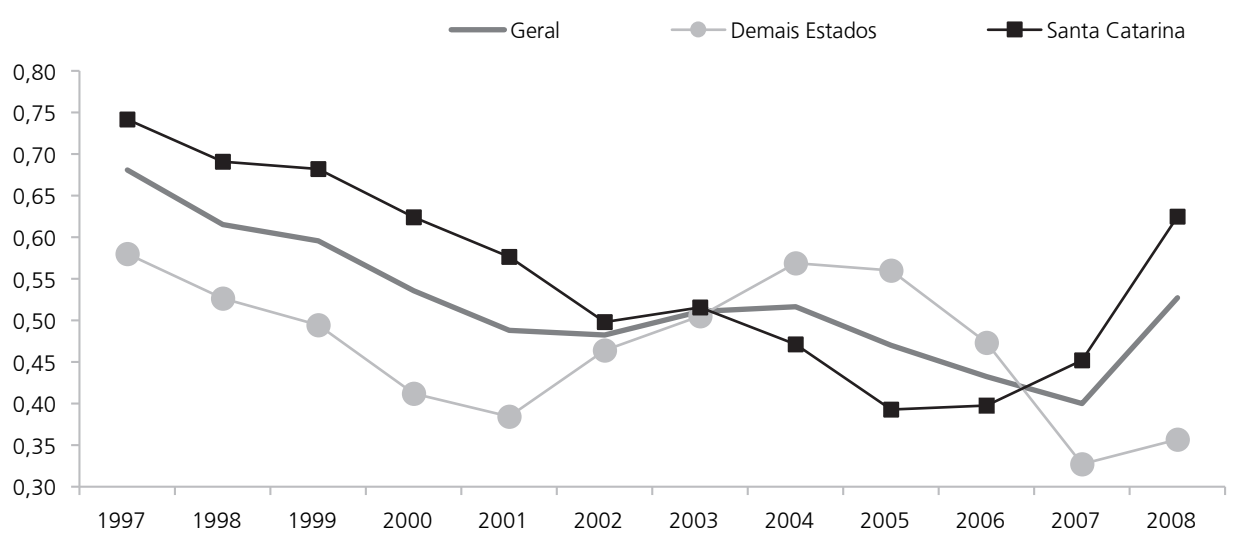

Fonte: BM\&FBovespa. Elaboraçāo dos autores.

\section{Considerações finais}

Após um extenso período de regulamentações aplicadas ao comércio internacional de bens têxteis e de vestuário, o ano de 2005 é considerado um marco na redução dessas práticas protecionistas. O presente trabalho procurou avaliar empiricamente, a partir de informações de empresas entre 1995 e 2008, os efeitos do fim do Acordo de Têxteis e Vestuários (AVT) sobre as duas indústrias no Brasil.

A literatura e as estatísticas utilizadas indicam que o centro de produção de bens têxteis e do vestuário foi deslocado para a Ásia, especialmente China e Índia, que, juntas, representaram cerca de $50 \%$ da produção mundial de 2006. Ademais, a expansão da demanda global por esses bens pode ter auxiliado a reduzir o impacto das mudanças decorrentes do término do AVT. Embora certos países tenham sido capazes de manter - e ampliar - os volumes das exportações desses bens, alguns em função de acordos preferenciais de comércio, com o aumento da concorrência internacional o Brasil tem enfrentado dificuldades para manter os níveis de produção e das suas exportações. As expectativas pessimistas sobre as condições competitivas da indústria local, em razão do cenário internacional, são agravadas pelo envelhecimento do parque industrial (investimentos insuficientes) nos anos 2000.

Este estudo estima a fronteira de produção estocástica para 13 empresas têxteis entre 1997 e 2008 pelo método de Battese e Coelli (1995). Duas ressalvas são 
necessárias: a amostra é relativamente pequena, prejudicando os resultados assintóticos; e a quase totalidade da amostra (11) é composta por empresas do setor têxtil. Apesar de essa característica impor limites aos resultados em relação à indústria de vestuários, a amostra espelha particularidades da indústria têxtil nacional: é mais competitiva em termos internacionais no segmento de tecidos de algodão (brins, segmento de cama, mesa, banho, etc.); e nesse segmento está presente a maioria das grandes empresas intensivas em capital - e de capital aberto, origem das fontes de informaçōes necessárias no modelo econométrico e, portanto, do viés da amostra.

Os resultados apontam que o progresso tecnológico (deslocamento da fronteira de produção) foi uma constante ao longo do período e os fatores capital e trabalho mostraram-se complementares. De acordo com as estimativas, a eficiência das empresas brasileiras do setor têxtil e de vestuário aumenta quanto maior a idade da firma e menor o seu estoque. A primeira evidência corrobora que empresas mais antigas usufruem de redes de fornecimento mais bem estabelecidas. No conjunto, as firmas aumentaram a produtividade total dos fatores após o fim do AVT, notadamente, por conta do progresso tecnológico. Entretanto, a eficiência diminuiu logo após o fim do AVT, embora tenha retornado a patamares estatisticamente não diferenciados ao do período imediatamente anterior ao fim do AVT.

A diferenciação das empresas segundo sua localização mostrou-se relevante. $\mathrm{O}$ incremento do fator trabalho levaria a um produto maior para aquelas localizadas em Santa Catarina comparativamente às dos "demais Estados", enquanto o fator capital adiciona maior proporção de produto às empresas sediadas na última região. Além disso, o incremento de produto decorrente do progresso tecnológico é maior para as firmas catarinenses, que apresentam aumento da produtividade total de fatores (determinada pelo componente de mudança técnica) a partir de 2006, diferentemente daquelas localizadas nos demais Estados.

Em geral, as firmas de Santa Catarina foram mais eficientes e parecem esboçar uma reação para a recuperação da eficiência após o fim do AVT. Em contraste, aquelas localizadas nos demais Estados apresentam uma contínua queda de eficiência após o fim do AVT. O papel do polo regional de produção de Santa Catarina para o Brasil é reforçado pelas evidências do presente estudo após o fim do AVT, merecendo destaque no caso de uma política setorial (apesar de se tratar das grandes empresas brasileiras de capital aberto). Uma ressalva é que, possivelmente, a maior parte da pressão por competitividade não seja devida ao fim do AVT a partir de 2005, mas sim ao fim do memorando de entendimento entre Brasil e China, em 2008.

Com base nos resultados e considerações apresentados, parece que as decisōes tomadas pelas empresas examinadas neste estudo em reação ao fim do AVT são dis- 
tintas. Se em relação às empresas catarinenses os resultados sugerem que tal reação ocorreu às vésperas do final do acordo, para aquelas dos "demais Estados", a produtividade total dos fatores e a eficiência média desenham um cenário sombrio, ou seja, de problemas com a concorrência internacional. Se generalizarmos esses resultados, também o conjunto das empresas das duas indústrias deverá passar por dificuldades, pois este estudo considerou, em sua maioria, as grandes empresas do setor têxtil, para as quais as vantagens - por exemplo, da China ou na Índia - relativas à oferta e ao custo do fator trabalho não são tão relevantes quanto para a indústria do vestuário. Em suma, não parece ter havido um planejamento prévio que contemplasse medidas compensatórias aos impactos esperados pela extinção das cotas de importação dos produtos têxteis e de vestuário. Assim, parece estar sendo confirmado o receio sobre a capacidade de reação das empresas brasileiras expresso na literatura consultada.

\section{Referências bibliográficas}

AMARAL, D. F. Efeito do fim do Acordo Multifibras sobre a produção e o emprego dos setores têxtil e de vestuário no Brasil. Dissertação (Mestrado), Escola Superior de Agricultura "Luiz de Queiroz", Piracicaba, 2008.

BHANDARI, A. K.; MAITI, P. Efficiency of Indian manufacturing firms: textile industry as case study. International Journal of Business and Economics, v. 6, n. 1, 2007.

BATTESE, G. E.; COELLI, T. J. A model for Technical Inefficiency effects in a Stochastic Frontier Production Function for Panel Data. Empirical Economics, v. 20, n. 2, 1995.

BATTESE, G. E.; CORRA, G. S. Estimation of a production frontier model: with application to the pastoral zone of eastern Australia. Australian Journal of Agricultural Economics, v. 21, n. 3, 1977.

COELLI, T. J.; RAO, D. S. P.; O'DONNELL, C. J.; BATTESE, G. E. An introduction to efficiency and productivity analysis. $2^{\mathrm{a}} \mathrm{ed}$. Springer, 2005.

COSTA, A. C. R.; ROCHA, E. R. P. Panorama da cadeia produtiva têxtil e de confecçôes e a questão da inovação. BNDES Setorial, Rio de Janeiro, n. 29, 2009.

FEENSTRA, R. C. Advanced international trade: theory and evidence. Princeton: Princeton University Press, 2004.

GEREFFI, G. New offshoring of jobs and global development. ILO Social Policy Lecture. Genebra, 2006.

GORINI, A. P. F. Panorama do setor têxtil no Brasil e no mundo: reestruturação e perspectivas. BNDES Setorial, Rio de Janeiro, n. 12, 2000. 
Diogo de Prince Mendonça, Ariene da Silva Salgueiro, Rogério Gomes

GREENE, W. H. The econometric Approach to Efficiency Analysis. In: FRIED, H.; LOVELL, K.; SCHMIDT, S. The measurement of productive efficiency and productivity. Oxford University Press, 2007.

HARRIGAN, J.; BARROWS, G. Testing the theory of trade policy: evidence from the abrupt end of the multifiber arrangement. The Review of Economics and Statistics, v. 91, n, 2, 2009.

KODDE, D. A.; PALM, F. C. Wald criteria for jointly testing equality and inequality restrictions. Econometrica, v. 54, n. 5, 1986.

LALL, S. V.; RODRIGO, G. C. Perspectives on the source of heterogeneity in Indian Industry. World Development, v. 29, n. 12, 2001.

LOPES, S. S. O Brasil e o Acordo Multifibras. Dissertação (Mestrado), Pontífica Universidade Católica do Rio de janeiro, 1994.

MARTIN, M. F.U.S. clothing and textile trade with China and the world: trends since the end of quotas. Congressional Research Service Report for Congress, 2007.

NORDAS, H. K. The global textile and clothing industry post the agreement on textiles and clothing. Suíça: World Trade Organization, 2004.

OCDE. <http://stats.oecd.org/Index.aspx>. Acesso em: março de 2011.

PROCHNIK, V. A cadeia textil/confecçôes perante os desafios da Alca e do acordo commercial com a União Européia. Economia, Niterói, v. 4, n. 1, 2003.

SEYOUM, B. Trade liberalization and patterns of strategic adjustment in the US textiles and clothing industry. International Business Review, n. 16, 2007.

SHEPHARD, R. W. The theory of cost and production functions. Princeton University Press, 1970.

UNIDO. United Nations for Industrial Development (Indstat4, 2010), 2010.

ENDEREÇOS PARA CORRESPONDENCIA

Diogo de Prince Mendonça - dioted@gmail.com

Grupo de Estudos de Economia Industrial - Departamento de Economia (Unesp/Fclar)

Rodovia Araraquara/Jaú, Km 1

14800-901 - Araraquara (SP)

Ariene da Silva Salgueiro - arienesalgueiro@yahoo.com.br

Grupo de Estudos de Economia Industrial - Departamento de Economia (Unesp/Fclar)

Rodovia Araraquara/Jaú, Km 1

14800-901 - Araraquara (SP)

Rogério Gomes - rgomes@fclar.unesp.br

Grupo de Estudos de Economia Industrial - Departamento de Economia (Unesp/Fclar)

Rodovia Araraquara/Jaú, Km 1

14800-901 - Araraquara (SP) 